\title{
Effects of orthodontic treatment with activator appliance on patients with skeletal Class II malocclusion: a systematic review and meta-analysis
}

\author{
Jiye Xie ${ }^{1 \#}$, Chunrong Huang ${ }^{2 \#}$, Kang Yin ${ }^{3}$, Juyoung Park ${ }^{4}$, Yanhua $\mathrm{Xu}^{3}$ \\ ${ }^{1}$ First Clinic, School and Hospital of Stomatology, Kunming Medical University, Kunming, China; ${ }^{2}$ Department of Stomatology, Yunnan Provincial \\ Hospital of Traditional Chinese Medicine, Kunming, China; ${ }^{3}$ Department of Orthodontics, School and Hospital of Stomatology, Kunming Medical \\ University, Kunming, China; ${ }^{4}$ Department of Orthodontics, University of Pennsylvania, School of Dental Medicine, The Robert Schattner Center, \\ Philadelphia, PA, USA \\ Contributions: (I) Conception and design: J Xie, C Huang; (II) Administrative support: Y Xu; (III) Provision of study materials or patients: K Yin, \\ J Park, Y Xu; (IV) Collection and assembly of data: J Xie, C Huang; (V) Data analysis and interpretation: J Xie, C Huang; (VI) Manuscript writing: \\ All authors; (VII) Final approval of manuscript: All authors. \\ \#These authors contributed equally to this work. \\ Correspondence to: Prof. Dr. Yanhua Xu. Department of Orthodontics, School and Hospital of Stomatology, Kunming Medical University, 1088 \\ Middle Haiyuan Road, High-tech Zone, Kunming 650106, China. Email: xuyanhua18@163.com.
}

\begin{abstract}
Background: This systematic review aimed to evaluate and compare the treatment effects of activator appliances on untreated class II skeletal malocclusion patients in terms of skeletal, dental, and soft tissue changes.

Methods: We searched 11 databases from January 1966 to May 2021 for randomized and clinical controlled trials that compared the treatment effects of activator appliances on untreated Class II skeletal malocclusion patients. All data were analyzed using RevMan 5.3 software.
\end{abstract}

Results: According to the inclusion/exclusion criteria, 16 articles qualified for the final analysis. Thirteen outcome indicators of teeth, bone tissue, and soft tissue were compared and analyzed: $\mathrm{SNA}^{\circ}, \mathrm{SNB}^{\circ}$, $\mathrm{ANB}^{\circ}, \mathrm{SN}-\mathrm{MP}^{\circ}, \mathrm{ANS}^{\mathrm{Me}}$, Co-Gn, Go-Me, overjet, overbite, U1-SN${ }^{\circ}, \mathrm{L} 1-\mathrm{MP}^{\circ}, \mathrm{UL}-\mathrm{E}$, and LL-E. Five randomized controlled trials (RCTs) evaluations were of medium quality, and 11 controlled clinical trials (CCTs) evaluations were of B grade. Bone tissue changes: compared with the untreated group, the SNA and ANB decreased, and the SNB, SN-MP, ANS-Me, Co-Gn, and Go-Me increased after activator appliance treatment, and the differences were statistically significant $(\mathrm{P}<0.001)$. Dental changes: compared with the untreated group, the overjet, overbite and U1-SN in the treated group decreased significantly, while the L1MP increased significantly $(\mathrm{P}<0.0001)$. Soft tissue changes: compared with untreated patients, the UL-E of patients treated with an activator appliance decreased significantly $(\mathrm{P}<0.0001)$; however, there was no significant difference in the LL-E between the two groups $(\mathrm{P}=0.09)$.

Discussion: Since the imprecision and high level of heterogeneity of the articles, further large-sample and high-quality clinical trials are necessary to evaluate effects of orthodontic treatment with activator appliance on patients with skeletal Class II malocclusion. In addition, this study failed to explore the long-term stability of activator treatment, so long-term studies are needed to assess the stability of its effect on the skeletal, dental, and soft tissue changes

Keywords: Systematic review; activator appliance; skeletal Class II malocclusion

Submitted Sep 30, 2021. Accepted for publication Dec 06, 2021.

doi: 10.21037/apm-21-3205

View this article at: https://dx.doi.org/10.21037/apm-21-3205

\footnotetext{
^ ORCID: 0000-0002-6805-1299.
} 


\section{Introduction}

Skeletal Class II malocclusion is one of the most common malocclusions. In skeletal Class II malocclusion, mandibular retrusion is one of the main contributing factors in approximately one-third of the population (1). The main target in treating skeletal Class II malocclusion is to correct the skeletal discrepancy, eliminate oral dysfunction, and achieve an optimal facial profile $(2,3)$. For this purpose, different removable functional appliances, such as an activator, bionator, Twin-Block, and Herbst appliances, have been widely used for more than a century. Activators are widely used to treat skeletal Class II malocclusion (4).

Numerous studies have shown that the activator affects the dentoalveolar region $(2,4,5)$. However, there are some arguments over the orthopedic effects of the activators. Some authors claim that the activators can promote the growth of the mandible (6) and inhibit the growth of the maxilla (7). Others believe that activators have no significant effect on the growth of the mandible $(8,9)$. The correction of class II malocclusion is mainly the result of tooth compensation and skeleton position change (10).

Therefore, whether an activator appliance can stimulate an underlying mandibular growth pattern or leads only to dentoalveolar changes remains controversial. Previous studies, which include systematic reviews, mainly compared the activator and other appliances. Thus, it is impossible to clarify the effects of activator appliances on the patient's skeletal, dental, and soft tissue after activator appliance treatment. The objective of the current study was to evaluate the skeletal, dental, and soft tissue changes that occur during treatment with activator appliances and evaluate the treatment effects of activators by comparison with an untreated Class II skeletal malocclusion control group.

We present the following article in accordance with the PRISMA reporting checklist (available at https://dx.doi. org/10.21037/apm-21-3205).

\section{Methods}

\section{Search strategy}

An electronic literature search was carried out using the PubMed, OVID, Cochrane Library, Science Direct, Wiley Online Library, EMBASE, Web of Science, China Biology Medicine Disc (CBM), China National Knowledge Infrastructure (CNKI), Science and Technology Journal Database (CSTJ), and Wanfang databases. Terms used in the search included: "Class II", "Angle Class II", "Class II malocclusion", "Class II skeletal malocclusion", "Andresen activator", "Activator", "Activator appliances", and "removable functional appliances". Manually, the reference lists of the selected studies were also searched for additional related publications that were missed in the database searches.

\section{Inclusion criteria}

Studies were selected if they satisfied all the following inclusion criteria: (I) Publication date from January 1966 to May 2021; (II) randomized controlled trials (RCTs) or clinical controlled trials (CCTs) as well as prospective and retrospective controlled studies; (III) original studies based on humans; (IV) studies conducted on growing patients with Class II skeletal malocclusion and mandibular skeletal retrusion; (V) the activator was used in the experimental group to correct malocclusion, and the control group was untreated; and (VI) lateral cephalogram measurement analysis assessed skeletal, dental, and soft tissue movements.

\section{Exclusion criteria}

The exclusion criteria were as follows: (I) clinical trials that evaluated the effects between activators and other removable functional appliances, such as Twin Block; (II) study subjects treated by extraction, orthognathic surgery, or activator combined with bracket or fixed functional appliances; (III) studies involving data analyzed by electromyography and three-dimensional imaging technology; (IV) animal experiments, materials research, model research, or related basic research; and (V) case reports, reviews, or letters.

\section{Data extraction and quality analysis}

Data from the selected studies were extracted and recorded independently by two authors (J Xie and C Huang) and in duplicate using a customized data collection form on the following items: author and year of published articles, study design, numbers, sex, age, whole treatment time, and daily wearing time.

Quality assessment of the RCTs was performed according to the standards described in the Cochrane Handbook for Systematic Reviews of Interventions (version 5.1.0) (11). The quality scores were calculated by a modified version of the method described by Jadad (12). The quality evaluation of the CCTs was performed according to the standards described in the Cochrane Handbook for Systematic Reviews Interventions. Each article's methods and results 
sections were independently read and scored by two authors (J Xie and C Huang). Next, the authors discussed their extracted data, and disagreements were resolved by further re-reading and discussion.

\section{Statistical analyses}

In this systematic review, evaluation of the activator effects mainly included the following thirteen aspects: (I) the angle between the $\mathrm{SN}$ plane and the NA plane $\left(\mathrm{SNA}^{\circ}\right)$; (II) the angle between the $\mathrm{SN}$ plane and the $\mathrm{NB}$ plane $\left(\mathrm{SNB}^{\circ}\right)$; (III) SNA-SNB $\left(\mathrm{ANB}^{\circ}\right)$; (IV) the inclination of the mandibular plane to the cranial base $\left(\mathrm{SN}-\mathrm{MP}^{\circ}\right) ;(\mathrm{V})$ the anterior nasal spine to the menton points (ANS-Me, mm); (VI) CondilionGnation (Co-Gn, mm); (VII) Condilion-Menton (Go-Me, $\mathrm{mm}$ ); (VIII) overjet; (IX) overbite; (X) the axial inclination of the maxillary central incisor to the $\mathrm{SN}$ plane $\left(\mathrm{U}^{-}-\mathrm{SN}^{\circ}\right)$; (XI) the axial inclination of the mandibular central incisor to the MP plane (L1-MP); (XII) the upper lip to the E plane (UL-E, $\mathrm{mm}$ ); and (XIII) the lower lip to the E plane (UL-E, mm).

The results of multiple studies were statistically aggregated (if possible) with Review Manager 5.3 software using the weighted mean differences (WMD) and 95\% confidence intervals (CIs). Cochrane's test ( $\mathrm{I}^{2}$ test) assessed statistical heterogeneity within or between groups on the level of $\alpha=0.10$. The results were assessed by a fixed or random-effects model. The level of significance for the heterogeneity was set at $\mathrm{P}<0.05$. In the case of no substantial heterogeneity, the calculation of the overall comprehensive effect was based on the effect model. The outcomes were pooled with the random-effects model if there was evidence of heterogeneity.

Furthermore, sensitivity analyses were performed to deal with potential sources of heterogeneity. A meta-analysis was performed when possible; otherwise, a descriptive assessment was performed. Funnel plots were planned to assess publication bias if there were more than 10 studies for meta-analysis.

\section{Results}

\section{Description of the studies}

Finally, we included 16 studies (13-28), including five RCTs $(15,17,18,23,28)$ and eleven CCTs $(13,14,16,19-22,24-27)$. The characteristics of the studies, including author, year, study design, number of patients, age in years, treatment time, appliance wear, and outcome, are shown in Table 1.
The study selection process is demonstrated in a PRISMA flow chart (Figure 1).

\section{Methodological quality of the included studies}

Of the 16 included studies, five RCTs $(15,17,18,23,28)$ were high quality, and eleven CCTs $(13,14,16,19-22,24-27)$ were B grade. The methodological quality of the RCTs and CCTs are presented in Tables 2,3, respectively.

\section{Effects of interventions}

The results of the meta-analysis of cephalometric variables investigated in this review are shown in Table 4.

\section{Skeletal effects}

\section{SNA $^{\circ}$}

Thirteen articles $(13-17,19,20,22,24-27)$ reported the $\mathrm{SNA}^{\circ}$. A forest plot is displayed in Figure $2 \mathrm{~A}$. Due to existing heterogeneity $\left(\mathrm{I}^{2}=64 \%\right)$, a random-effects model was adopted. There was a significant difference between the activator appliance group and the untreated control group $(\mathrm{P}<0.0001)$, and the WMD $(95 \% \mathrm{CI})$ was $-0.52^{\circ}\left(-0.78^{\circ}\right.$, $\left.-0.27^{\circ}\right)$. The sensitivity analysis was performed, and the results showed that the removal of Dalci et al. (17) had only minor effects on the overall effect size and had no effect on significance, as indicated in Figure $2 B$.

\section{$\mathrm{SNB}^{\circ}$}

Thirteen studies $(13,14,16,17,19,20,22-27)$ investigated this outcome. The forest plot is shown in Figure $3 \mathrm{~A}$. Due to existing heterogeneity $\left(\mathrm{I}^{2}=77 \%\right)$, a random-effects model was adopted. As presented in Figure 3A, the WMD (95\% CI) between the two groups was $0.80^{\circ}\left(0.47^{\circ}, 1.14^{\circ}\right)$, and the difference between the groups was significant $(\mathrm{P}<0.00001)$. As indicated in Figure $3 B$, the sensitivity analysis suggested that the removal of each study had only minor effects on the overall effect size and had no effect on significance. The result indicated that the synthesis outcome was essentially unchanged upon the systematic removal of data.

\section{$\mathrm{ANB}^{\circ}$}

Eleven articles $(13,14,16,17,19,20,22,24-27)$ reported this outcome. A meta-analysis was performed (Figure 4); as shown in the forest plot, the WMD (95\% CI) was $-1.44^{\circ}$ $(-1.77,-1.10)$, the conclusions of all the studies were consistent, and $\mathrm{ANB}^{\circ}$ were significantly reduced in the 
Table 1 Characteristics of the included studies

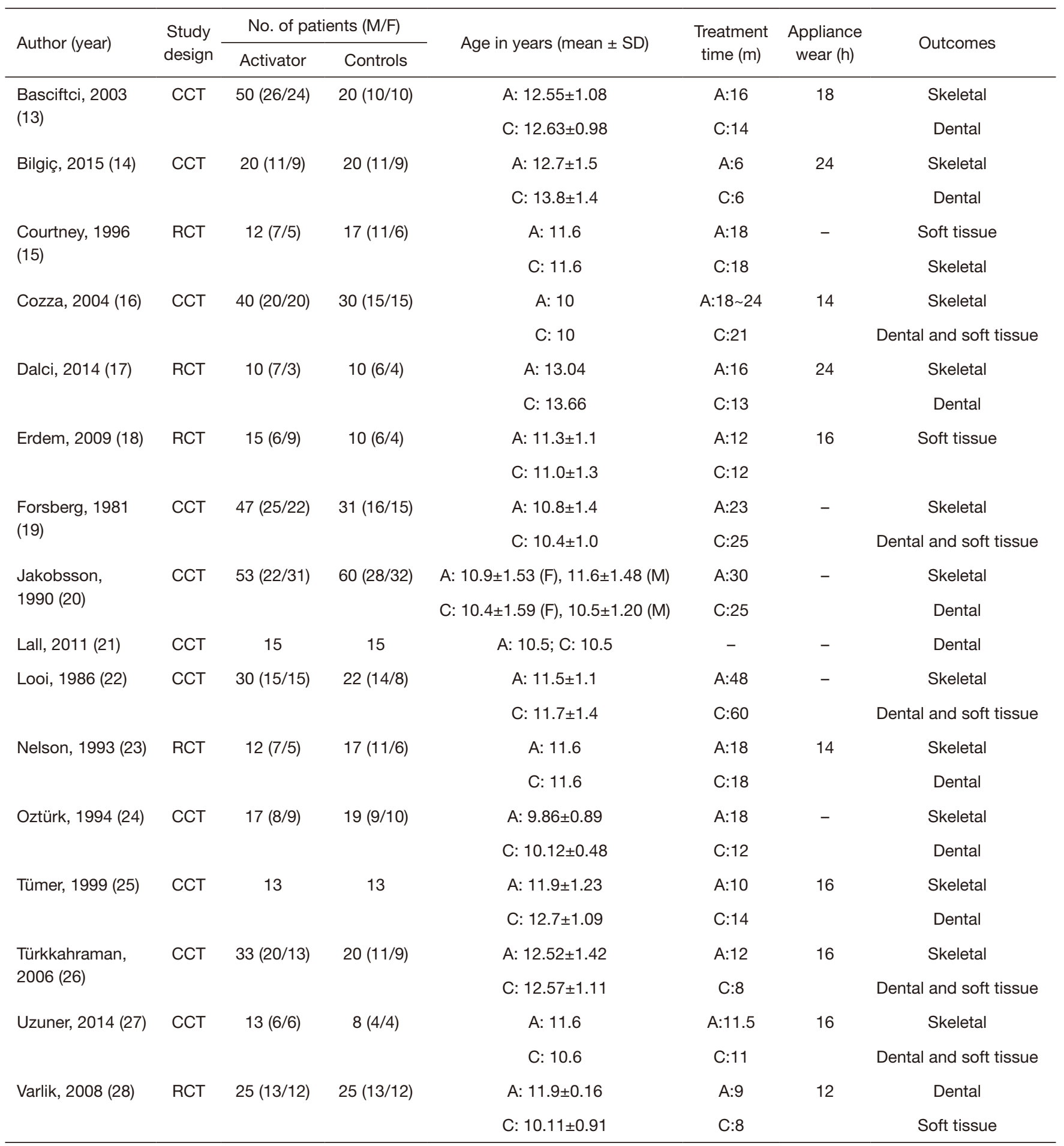

$\mathrm{RCT}$, randomized controlled trial; CCT, clinical controlled trial; A, activator group; C, untreated control group; M, male; F, female; m, month; h, hour. 

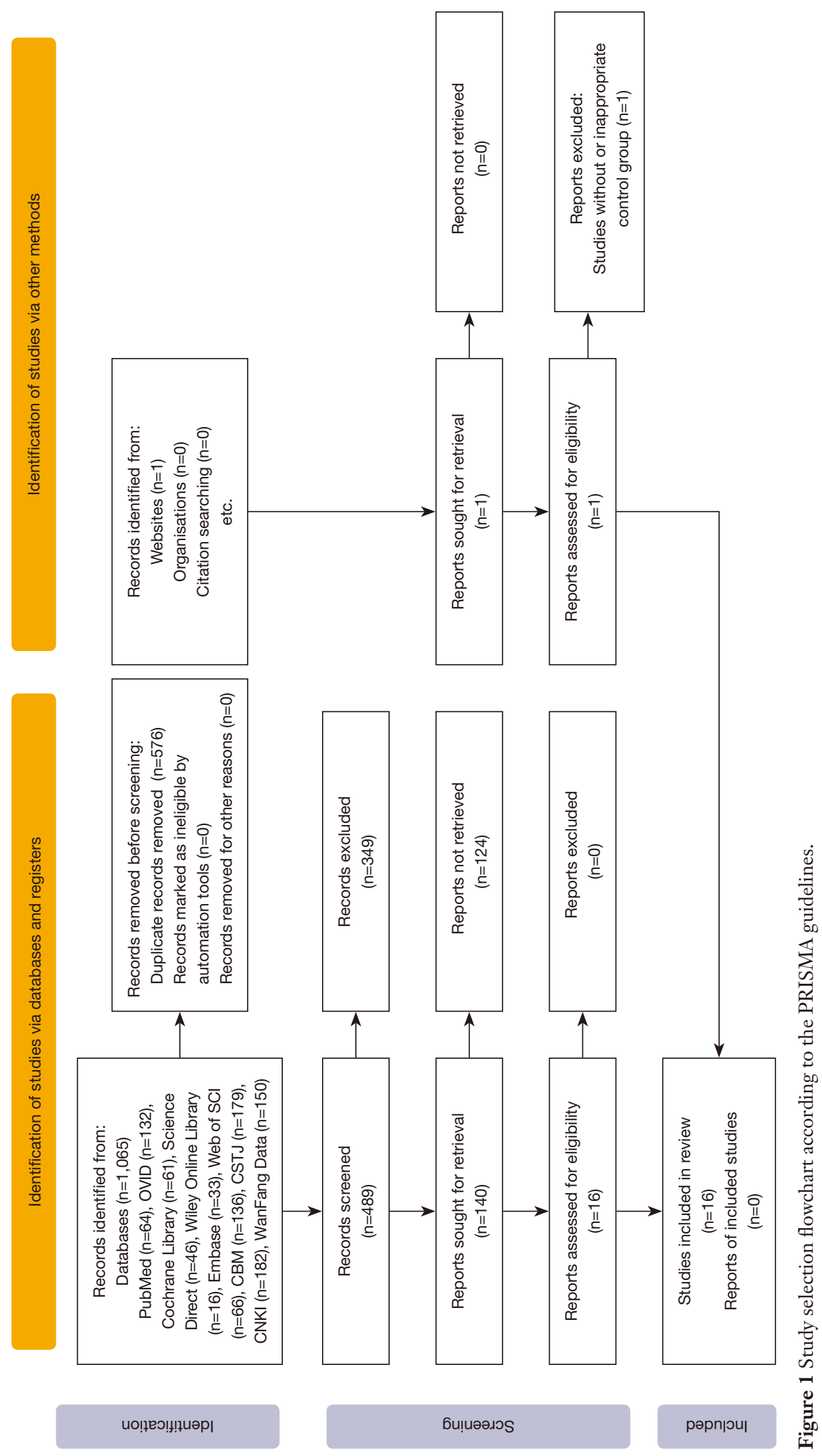
Table 2 Methodological quality of the selected RCTs*

\begin{tabular}{|c|c|c|c|c|c|c|c|c|}
\hline Study & $\begin{array}{c}\text { Random sequence } \\
\text { generation }\end{array}$ & $\begin{array}{c}\text { Allocation } \\
\text { concealment }\end{array}$ & Blinding & $\begin{array}{c}\text { Incomplete } \\
\text { outcome data }\end{array}$ & $\begin{array}{l}\text { Selective } \\
\text { reporting }\end{array}$ & $\begin{array}{l}\text { Other } \\
\text { bias }\end{array}$ & $\begin{array}{l}\text { Jadad } \\
\text { score }\end{array}$ & Quality \\
\hline Courtney, 1996 (15) & Unclear & Unclear & Unclear & Yes & Yes & Yes & 4 & High \\
\hline Erdem, 2009 (18) & Unclear & Unclear & Unclear & Yes & Yes & Yes & 4 & High \\
\hline
\end{tabular}

*, quality was categorized as low quality (1-3 Jadad scores) and high quality (4-7 Jadad scores). RCT, randomized controlled trial.

Table 3 Methodological quality of the selected CCTs*

\begin{tabular}{|c|c|c|c|c|c|c|c|c|}
\hline Study & Diagnostic criteria & $\begin{array}{l}\text { Grouping } \\
\text { method }\end{array}$ & Blinding & $\begin{array}{l}\text { Baseline } \\
\text { consistency }\end{array}$ & $\begin{array}{c}\text { Confounder } \\
\text { control }\end{array}$ & $\begin{array}{l}\text { Lost to } \\
\text { treatment }\end{array}$ & Score & Grade \\
\hline Basciftci, 2003 (13) & Clinical diagnosis & NR & NR & Good & Better & No lost & 7 & B \\
\hline Cozza, 2004 (16) & Clinical diagnosis & NR & NR & Good & Better & No lost & 7 & B \\
\hline Forsberg, 1981 (19) & Clinical diagnosis & NR & NR & Good & Good & No lost & 6 & B \\
\hline Lall, 2011 (21) & Clinical diagnosis & NR & NR & Good & Good & No lost & 6 & B \\
\hline Looi, 1986 (22) & Clinical diagnosis & NR & NR & Better & Better & No lost & 8 & B \\
\hline Oztürk, 1994 (24) & Clinical diagnosis & NR & NR & Good & Good & No lost & 6 & $\mathrm{~B}$ \\
\hline
\end{tabular}

*, quality was categorized as A grade (10-12 scores), B grade (6-9 scores), and C grade (0-5 scores). CCT, clinical controlled trial; NR, not reported.

activator appliance group compared with untreated patients.

\section{SN-MP ${ }^{\circ}$}

Six articles $(13,14,17,25-27)$ reported this outcome. A metaanalysis was performed (Figure 5). The WMD (95\% CI) between the activator appliance group and the untreated control group was $0.98^{\circ}\left(0.63^{\circ}, 1.33^{\circ}\right)$, and there was a significant difference between the two groups $(\mathrm{P}<0.00001)$.

\section{ANS-Me (mm)}

Seven articles $(14-17,24,25,27)$ reported the ANS-Me $(\mathrm{mm})$. A forest plot is shown in Figure 6A. The metaanalysis results showed significant heterogeneity among these seven trials $\left(\mathrm{P}<0.0001, \mathrm{I}^{2}=81 \%\right)$, so a random-effects model was adopted. As shown in Figure 6A, the WMD (95\% $\mathrm{CI})$ was $1.50 \mathrm{~mm}(0.53,2.47)$, and there was a significant difference between the two groups $(\mathrm{P}=0.002)$. The sensitivity analysis was performed, and results showed that the removal of Cozza et al. (16) and Oztürk et al. (24) had only minor effects on overall effect size and had no effect on significance, as indicated in Figure 6 B.

\section{Co-Gn (mm)}

Seven articles $(13,14,16,17,23,25,27)$ investigated the Co$\mathrm{Gn}(\mathrm{mm})$. The forest plot is shown in Figure 7A. A randomeffects model was adopted due to existing heterogeneity $\left(\mathrm{I}^{2}=77 \%\right)$. The figure showed that there was a significant difference between the activator appliance group and the untreated control group $(\mathrm{P}<0.00001)$, and the WMD 
Table 4 Meta-analysis results*

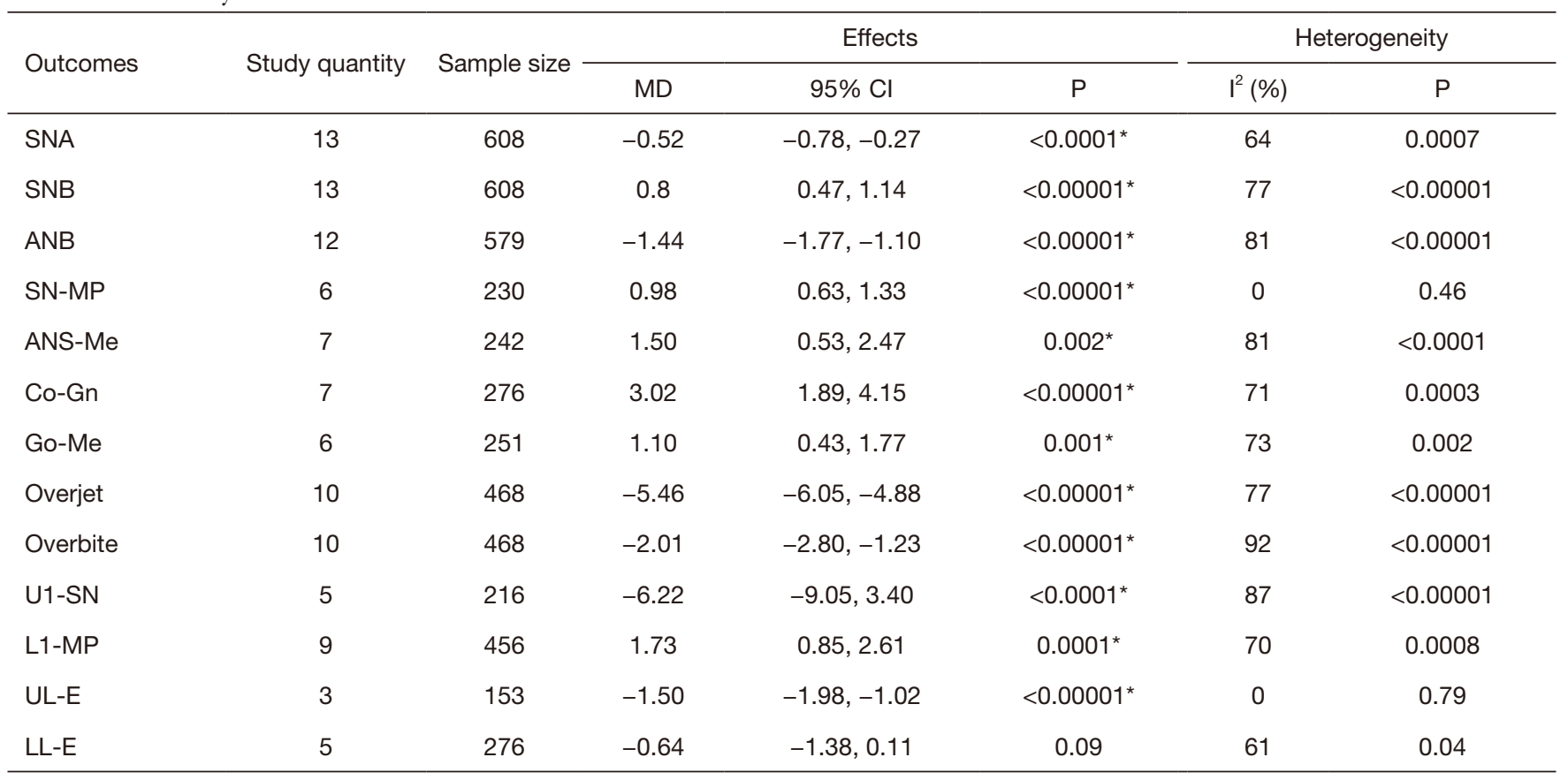

*, $\mathrm{P}<0.01$.

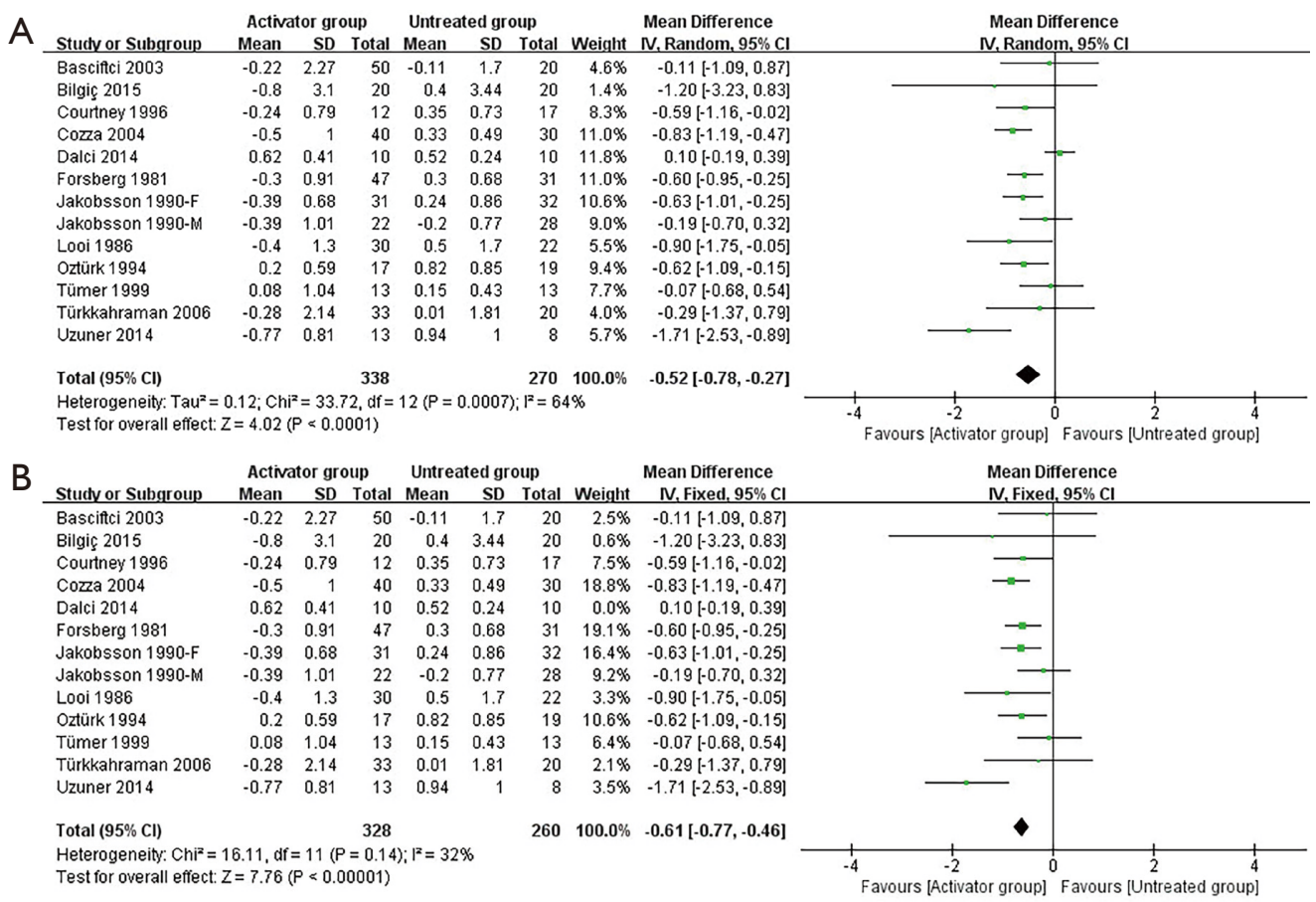

Figure 2 The meta-analysis and sensitivity analysis of the $\mathrm{SNA}^{\circ}$. (A) The meta-analysis of the $\mathrm{SNA}^{\circ}$; (B) the sensitivity analysis of the $\mathrm{SNA}^{\circ}$. 


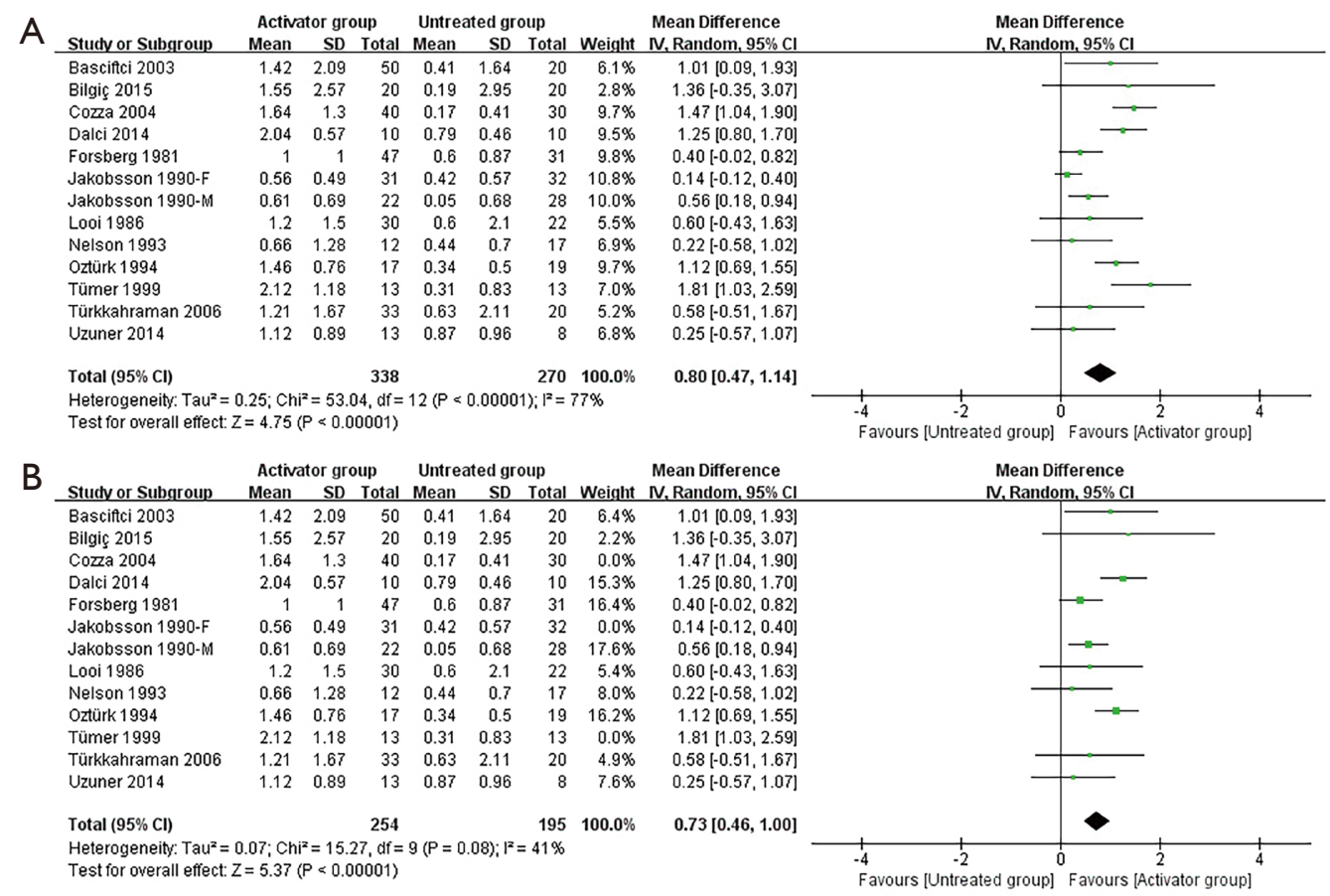

Figure 3 The meta-analysis and sensitivity analysis of the $\mathrm{SNB}^{\circ}$. (A) The meta-analysis of the $\mathrm{SNB}^{\circ}$; (B) the sensitivity analysis of the $\mathrm{SNB}^{\circ}$.

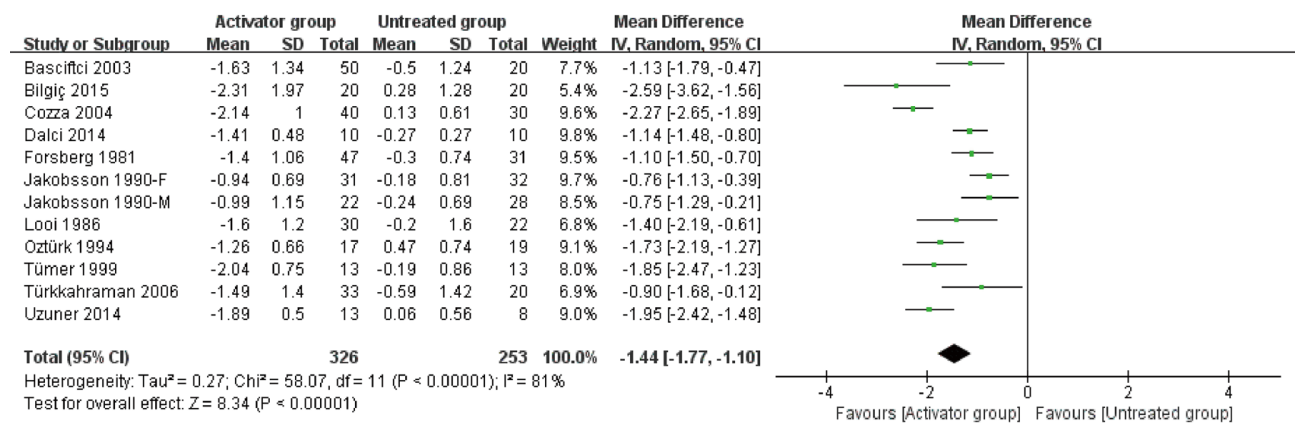

Figure 4 The meta-analysis of the $\mathrm{ANB}^{\circ}$.

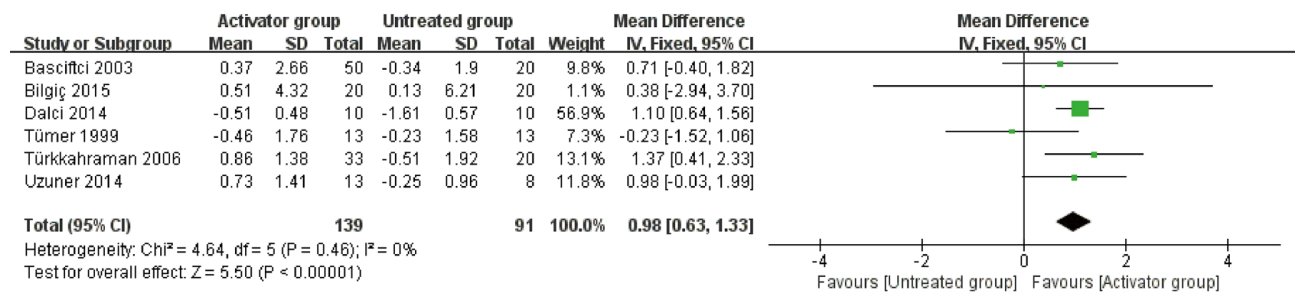

Figure 5 The meta-analysis of the $\mathrm{SN}-\mathrm{MP}^{\circ}$. 


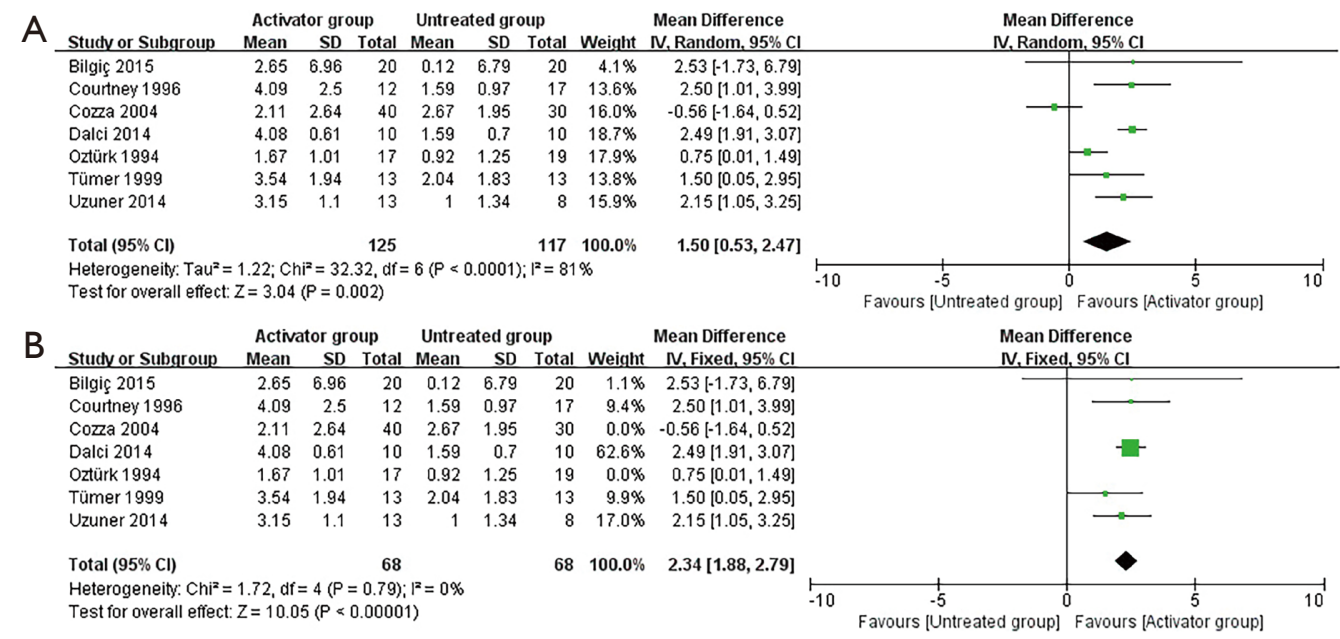

Figure 6 The meta-analysis and sensitivity analysis of the ANS-Me (mm). (A) The meta-analysis of the ANS-Me (mm); (B) the sensitivity analysis of the ANS-Me (mm).

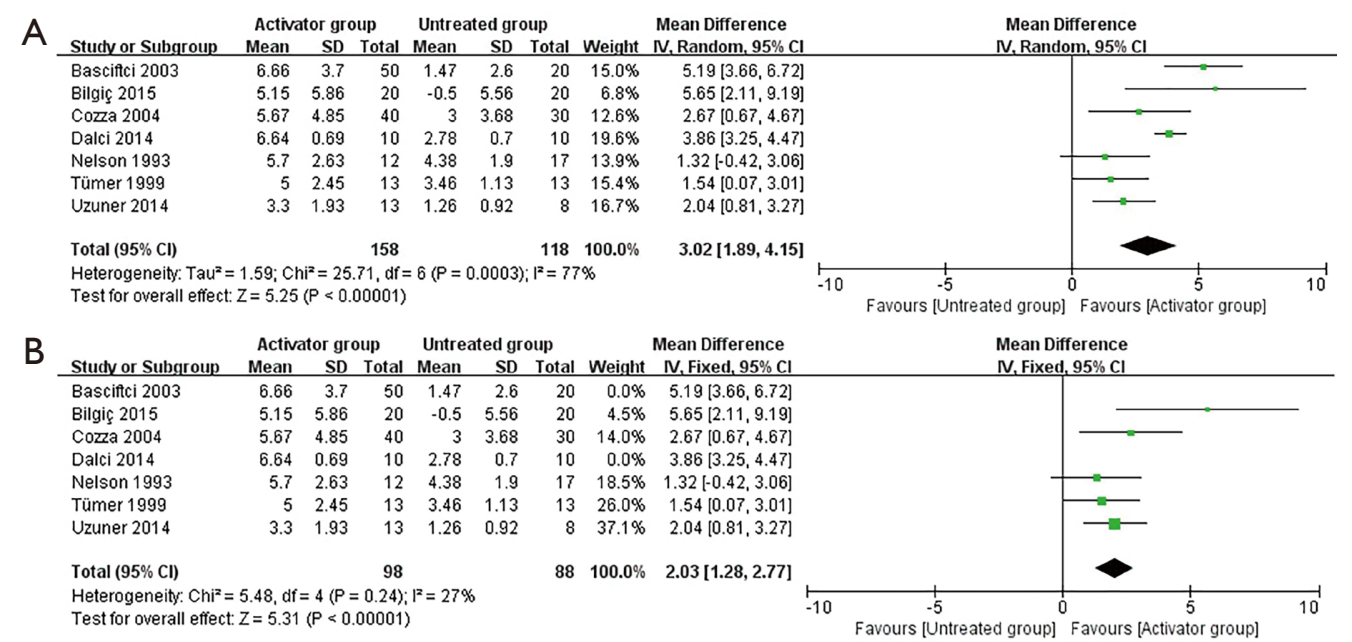

Figure 7 The meta-analysis and sensitivity analysis of the Co-Gn (mm). (A) The meta-analysis of the Co-Gn (mm); (B) the sensitivity analysis of the Co-Gn (mm).

(95\% CI) was $3.02 \mathrm{~mm}(1.89,4.15 \mathrm{~mm})$. As indicated in Figure $7 B$, the sensitivity analysis suggested that the removal of each study had only minor effects on overall effect size and had no effect on significance.

\section{Go-Me (mm)}

Six articles $(13,16,17,23-25)$ reported the Go-Me $(\mathrm{mm})$. A meta-analysis was performed (Figure $8 A$ ). Since there was significant heterogeneity among these studies, a randomeffects model was adopted. The WMD (95\% CI) between the two groups was $1.10 \mathrm{~mm}(0.43,1.77)$, and the difference was statistically significant $(\mathrm{P}=0.001)$. Sensitivity analysis was performed, and the result showed that the removal of Basciftci et al. (13) and Dalci et al. (17) had only minor effects on the overall effect size and had no effect on significance, as indicated in Figure $8 B$.

\section{Dental effects}

\section{Overjet (mm)}

Ten articles $(13-17,19,21,22,25,26)$ reported the overjet $(\mathrm{mm})$. A forest plot is demonstrated in Figure 9, which 


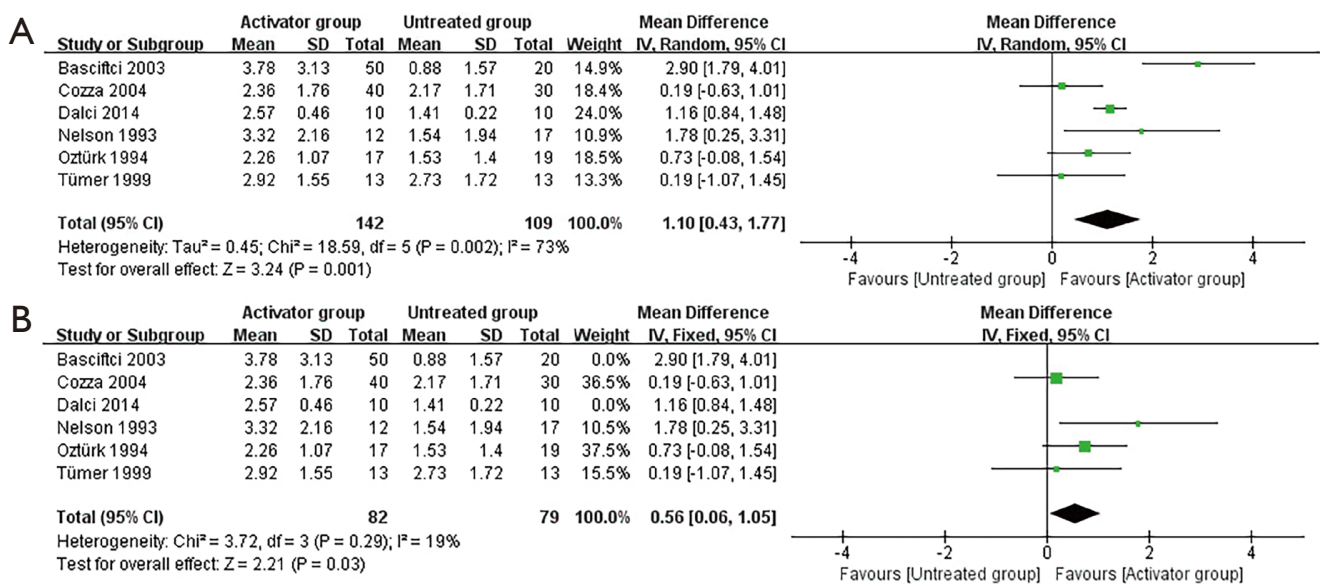

Figure 8 The meta-analysis and sensitivity analysis of the Go-Me (mm). (A) The meta-analysis of the Go-Me (mm); (B) the sensitivity analysis of the Go-Me (mm).

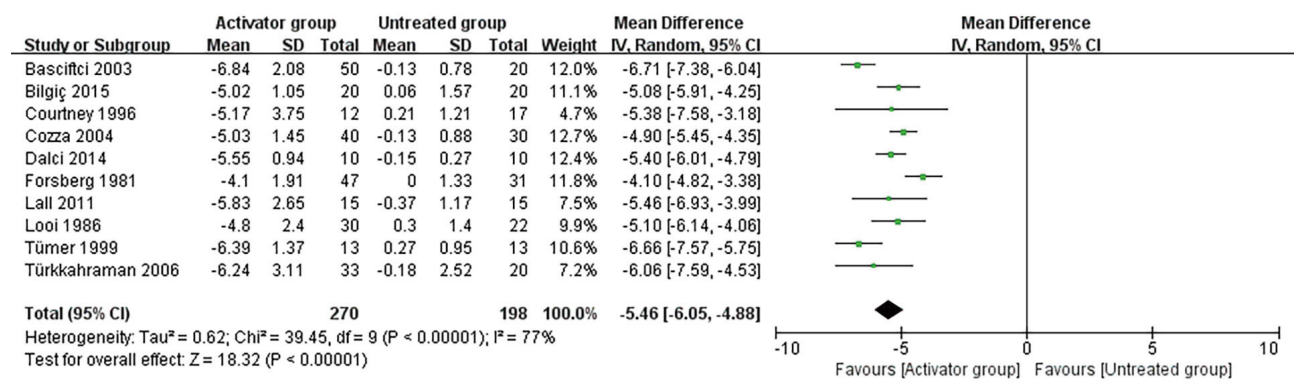

Figure 9 The meta-analysis of the overjet $(\mathrm{mm})$.

showed that there was a significant difference between the activator appliance group and the untreated control group $(\mathrm{P}<0.00001)$, and the WMD $(95 \% \mathrm{CI})$ was $-5.46 \mathrm{~mm}$ $(-6.05,-4.88 \mathrm{~mm})$. The conclusions of all the studies were consistent, and the overjet was significantly reduced in the activator appliance group compared with untreated patients.

\section{Overbite (mm)}

Ten articles $(13-17,19,21,22,25,26)$ reported the overbite $(\mathrm{mm})$. A meta-analysis was performed, and the forest plot is shown in Figure 10A. Due to existing heterogeneity $\left(\mathrm{I}^{2}=92 \%\right)$, a random-effects model was adopted. There was a significant difference between the activator appliance group and the untreated control group $(\mathrm{P}<0.00001)$, and the WMD (95\% CI) was $-2.01 \mathrm{~mm}(-2.80,-1.23 \mathrm{~mm})$. The sensitivity analysis suggested that the removal of four heterogeneous studies had no effect on significance, as indicated in Figure 10B.

\section{U1-SN}

Five studies $(13,14,21,25,28)$ investigated this outcome. The results of the meta-analysis showed that the WMD $(95 \% \mathrm{CI})$ was $-6.22^{\circ}\left(-9.05^{\circ},-3.40^{\circ}\right)$. The results showed that there was a significant difference between these two groups $(\mathrm{P}<0.0001)$, as shown in Figure 11, and the conclusions of all the studies were consistent. Moreover, the $\mathrm{U} 1-\mathrm{SN}^{\circ}$ were markedly reduced in the activator appliance group compared with untreated patients.

\section{L1-MP}

Nine articles $(13,14,16,20,21,24,25,27,28)$ were categorized into this study. The forest plot is shown in Figure 12A. Due to existing heterogeneity $\left(\mathrm{I}^{2}=70 \%\right)$, a random-effects model was adopted. The figure shows that there was a significant difference between the activator appliance group and the untreated control group $(\mathrm{P}=0.0001)$, and the WMD $(95 \% \mathrm{CI})$ was $1.73^{\circ}\left(0.85^{\circ}, 2.61^{\circ}\right)$. As indicated in 


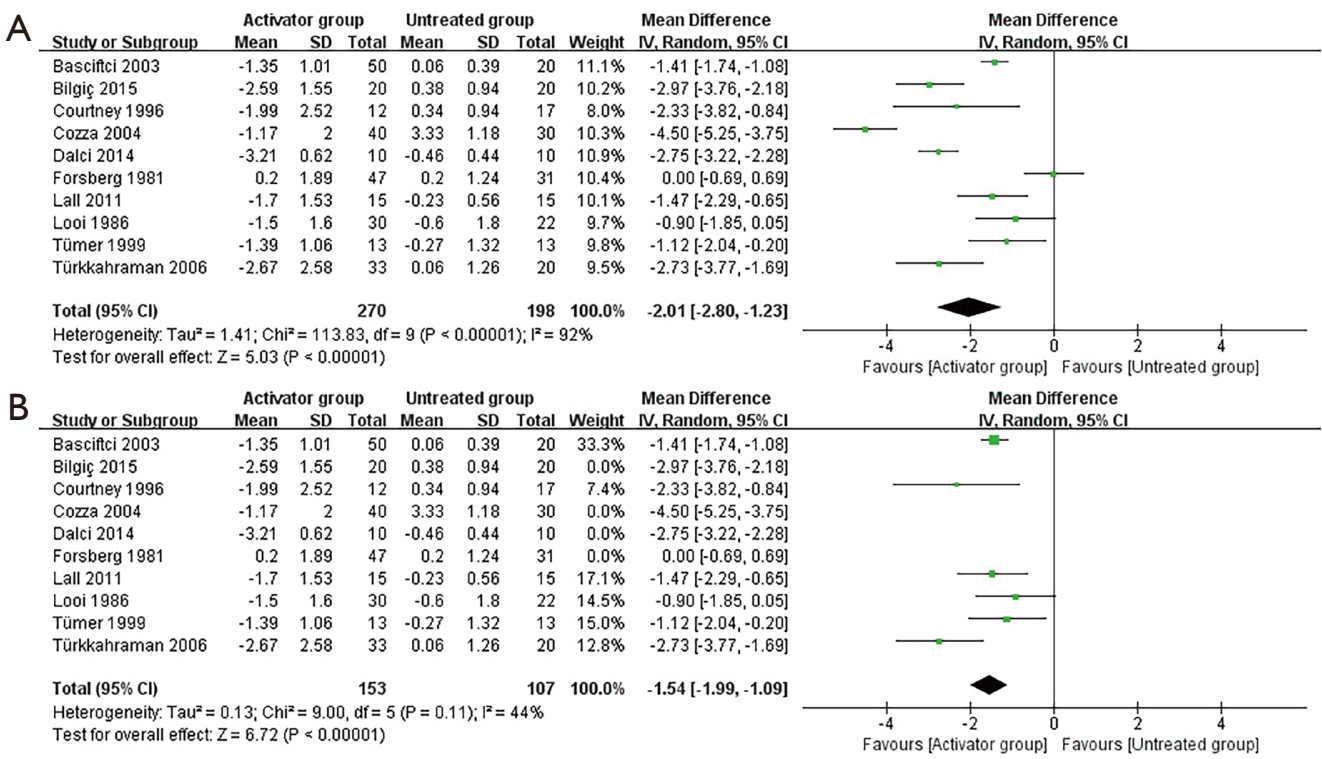

Figure 10 The meta-analysis and sensitivity analysis of the overbite (mm). (A) The meta-analysis of the overbite (mm); (B) the sensitivity analysis of the overbite (mm).

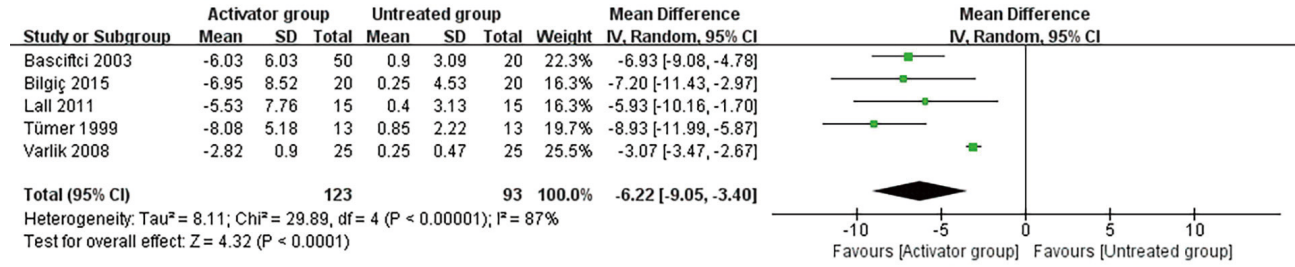

Figure 11 The meta-analysis of the U1-SN .

Figure $12 B$, the sensitivity analysis result showed there was no effect on significance.

\section{Soft tissue effects}

\section{UL-E (mm)}

Three articles $(18,19,28)$ investigated this outcome. A meta-analysis was performed, and the forest plot is shown in Figure 13. The WMD (95\% CI) between the activator appliance group and the untreated control group was $-1.50 \mathrm{~mm}(-1.98,-1.02 \mathrm{~mm})$, and the difference between the groups was significant $(\mathrm{P}<0.00001)$.

\section{LL-E (mm)}

Five articles $(16,18,19,26,28)$ reported the LL-E $(\mathrm{mm})$. The forest plot is shown in Figure 14A. The meta-analysis showed significant heterogeneity among these five trials
$\left(\mathrm{P}=0.04, \mathrm{I}^{2}=61 \%\right)$, so a random-effects model was adopted. The WMD (95\% CI) between the two groups was $-0.64 \mathrm{~mm}(-1.38,0.11 \mathrm{~mm})$, and no statistical significance was observed $(\mathrm{P}=0.09)$. The sensitivity analysis was performed, and the result showed that the WMD (95\% CI) between the two groups was $-0.93 \mathrm{~mm}(-1.43,-0.44 \mathrm{~mm})$, and the difference between the two groups was notable $(\mathrm{P}=0.002)$, as indicated in Figure $14 B$.

\section{Reporting biases}

Reporting biases could be assessed only for the metaanalyses of outcomes that included at least 10 studies. Therefore, $\mathrm{SNA}^{\circ}, \mathrm{SNB}^{\circ}, \mathrm{ANB}^{\circ}$, overjet, and overbite could be assessed. The funnel plots (Figure 15) were symmetrical, indicating that there was no obvious publication bias. 


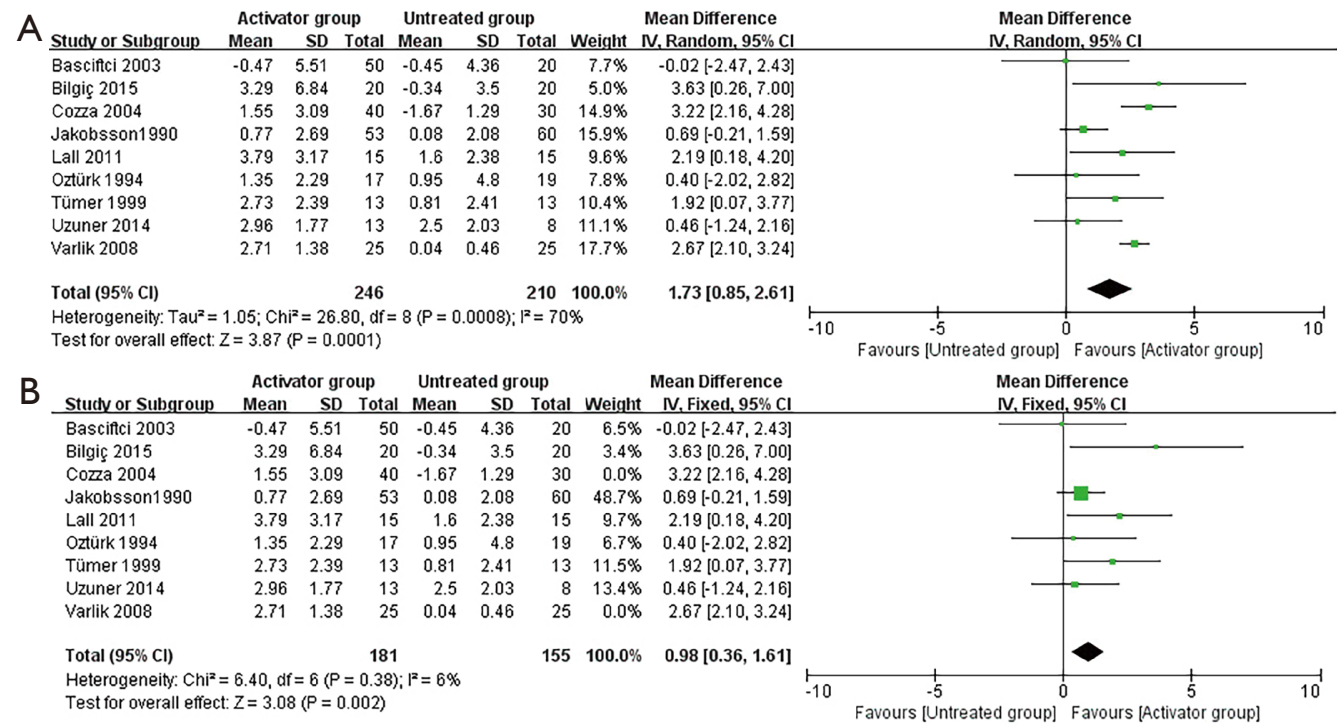

Figure 12 The meta-analysis and sensitivity analysis of the L1-MP ${ }^{\circ}$. (A) The meta-analysis of the L1-MP' (B) the sensitivity analysis of the L1-MP

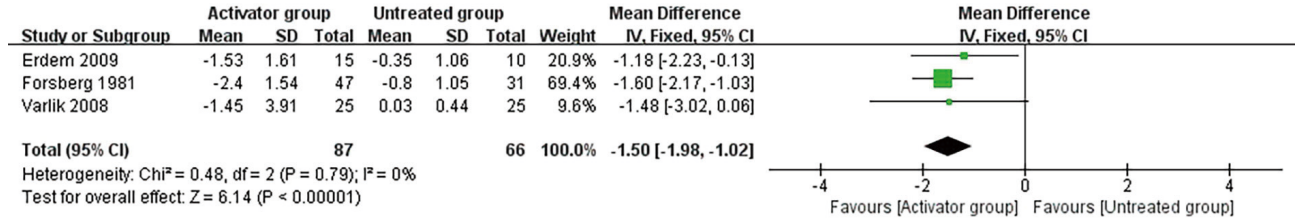

Figure 13 The meta-analysis of the UL-E (mm).

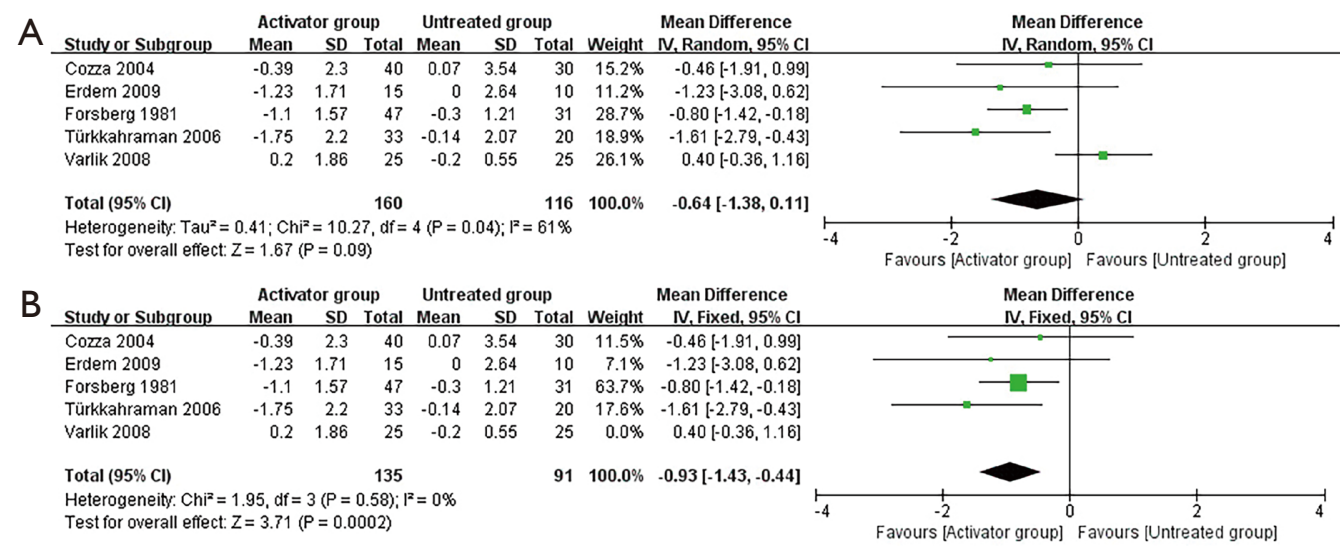

Figure 14 The meta-analysis and sensitivity analysis of the LL-E (mm). (A) The meta-analysis of the LL-E (mm); (B) the sensitivity analysis of the LL-E (mm). 

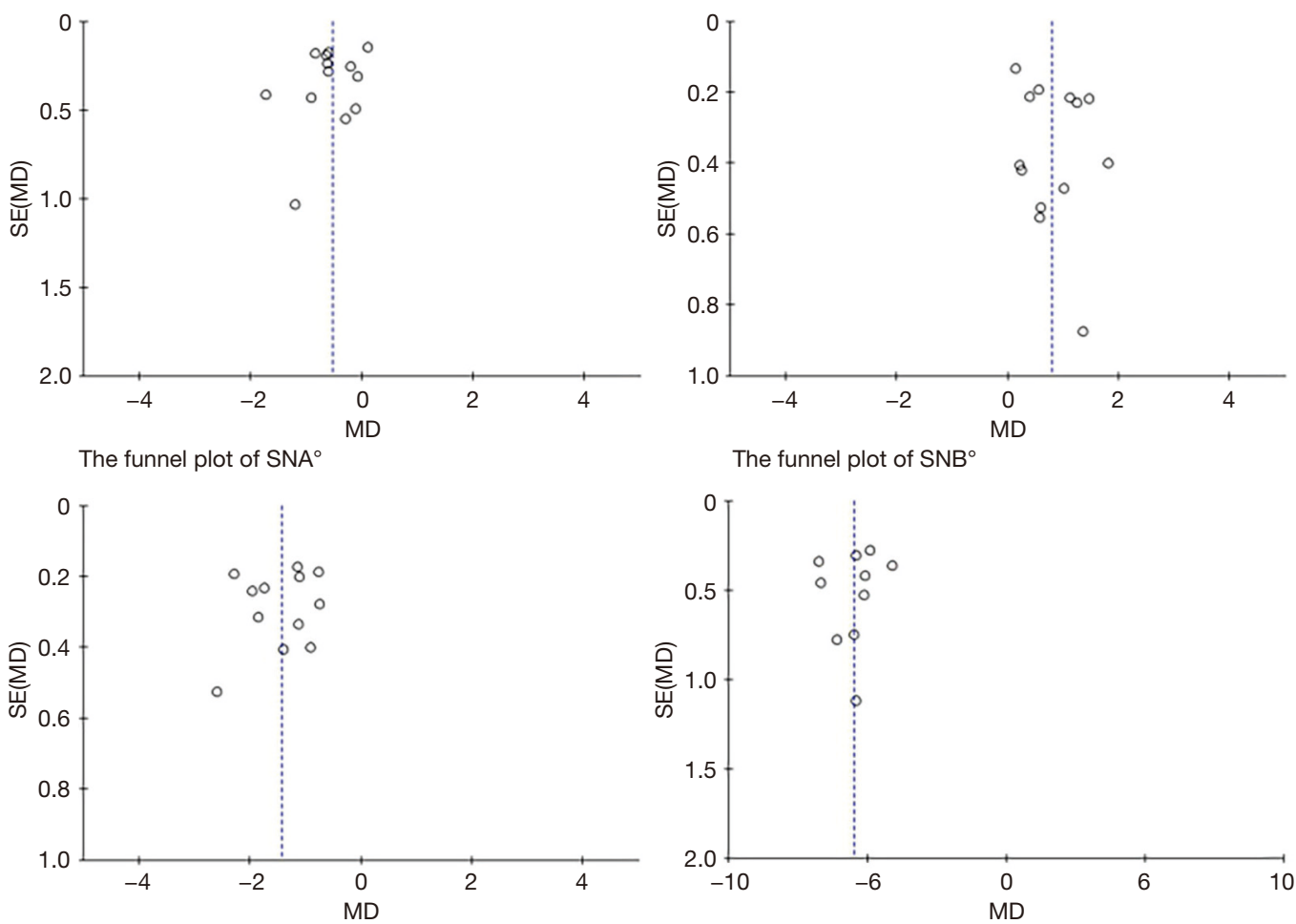

The funnel plot of ANB $^{\circ}$

The funnel plot of $\mathrm{SNB}^{\circ}$
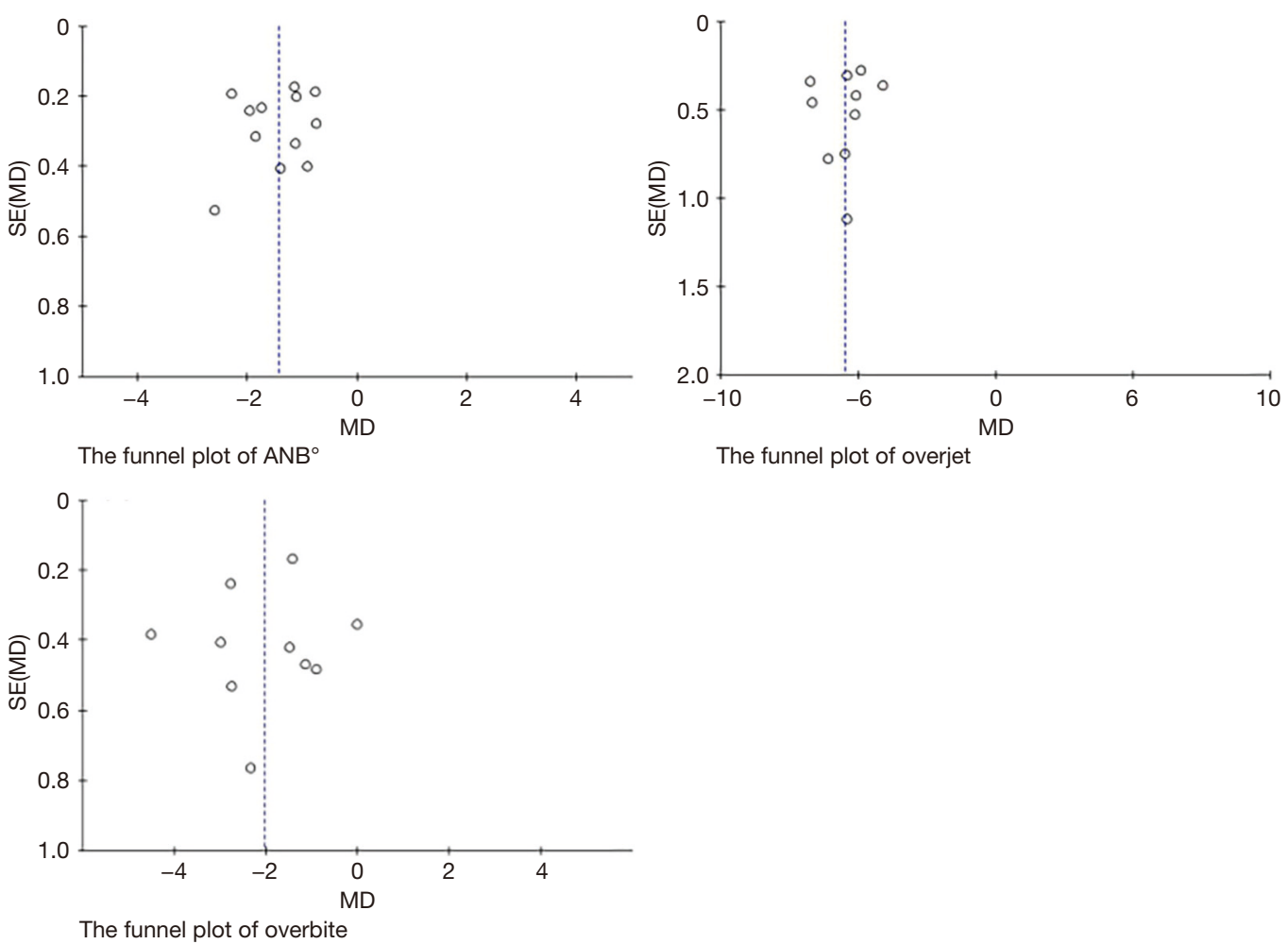

The funnel plot of overjet

Figure 15 The funnel plots of $\mathrm{SNA}^{\circ}, \mathrm{SNB}^{\circ}, \mathrm{ANB}^{\circ}$, overjet, and overbite. $\mathrm{MD}$, mean deviation.

\section{Discussion}

\section{Quality of the included studies}

RCTs have rarely been used in orthodontic studies, and the ethical issue of leaving a group of patients untreated is sensitive. Therefore, CCTs were included in this review. Five of these 16 included studies were RCTs, and the evaluation of quality indicated that all the RCTs $(15,17,18,23,28)$ were high quality (Table 2$)$. However, these studies had some methodological limitations. None of the five RCTs had sufficient information to determine whether allocation concealment or blinding was used in measuring the cephalometric parameters. Furthermore, only Varlik et al. (28) described the random assignment method. The remaining RCTs only mentioned the random assignment but did not describe the specific method. All eleven CCTs $(13,14,16,19-22,24-27)$ had clear diagnostic criteria and a consistent baseline. In addition, there were no obvious confounding factors or loss to follow-up. However, a grouping method or blinding related to the measurements was not mentioned in any of the CCTs. The results showed that all eleven CCTs were B grade (Table 3). 


\section{Effects of interventions}

\section{Skeletal effects}

The results showed that the maxilla exhibited normal growth in the untreated group. However, the activator group showed decreases in the SNA angle, relatively backward movement of Point A, and reduced maxillary growth. Moreover, the meta-analysis showed that there was a significant difference. Therefore, activator appliances limit the growth of the maxillary bone.

The activator group was compared with the untreated group, the SNB angle increased by $0.8^{\circ}$, the ANB angle decreased by $1.44^{\circ}$, the SN-MP increased by $0.98^{\circ}$, the ANS-Me increased by $1.50 \mathrm{~mm}$, and the mandibular length increased (Co-Gn: $3.02 \mathrm{~mm}$; Go-Me: $1.1 \mathrm{~mm}$ ), and the differences were statistically significant $(\mathrm{P}<0.01)$. These changes were due to the result of a simulation of condylar growth. Basciftci et al. (13) found that there is thickened new bone around the surface of the condyle after activator appliance treatment, which may be the reason for the increase in the height of the mandibular ramus and the comprehensive length of the mandible. This means that the activator appliance can provide clinically significant growth in the length of the total mandible and the mandible plane, which is beneficial to improving the positional relationship between the mandible and maxilla, and can effectively improve facial appearance.

\section{Dental effects}

The results showed that the overbite, overjet, and U1-SN angle decreased markedly in the activator group compared with the untreated group, but the L1-MP increased. The meta-analysis revealed significant differences in these outcomes $(\mathrm{P}<0.01)$.

After treatment with the activator, the overjet and overbite in growing patients with Class II skeletal malocclusion decreased significantly, resulting from the movement of mandibular protrusion, maxillary incisor retraction, and mandibular incisor lip inclination. The correction of teeth by the activator and the effect of bone reconstruction can significantly improve the profile appearance of patients, correct abnormal occlusion, and effectively reduce the adverse effects of Class II skeletal malocclusion. In addition, Batista et al. (29) showed that after activator appliance treatment, the protrusion of maxillary anterior teeth decreased notably, thus reducing the incidence of maxillary anterior teeth trauma.

\section{Soft tissue effects}

Improving the profile appearance is one of the most essential demands of patients with Class II skeletal malocclusion. In this study, two soft tissue outcomes, UL-E and LL-E, were involved.

Only three studies were included for UL-E, and the meta-analysis showed statistically significant differences between the two groups $(\mathrm{P}<0.01)$. Compared with untreated patients, the UL-E of the patients treated with the activator decreased, the upper lip retracted, and the protrusion decreased, which may be related to the apparent adduction of the maxillary incisors and the growth of the mandible (3).

Five studies $(16,18,19,26,28)$ included the LL-E. Of these, four studies suggested that patients treated with the activator had significantly decreased LL-E compared with the untreated group subjects. In contrast, Varlik et al. (28) reported the opposite conclusion. The results showed that the difference was statistically significant. Therefore, we cannot determine the effectiveness of the activator appliances for the LL-E with regard to unreliable methodology and results.

The number of studies on soft tissue changes is small, and the results are controversial. More high-quality RCTs are needed to obtain valuable evidence of the changes in soft tissue in growing patients with Class II skeletal malocclusion.

The main strength of this systematic review was the inclusion of studies evaluating skeletal, dental, and soft tissue changes, which compared activator appliance treatment with an untreated group. Despite extensive and accurate searches, this systematic review only included 16 eligible studies. A few studies were included for some outcome indicators, and the sample size was small. The quality evaluation results showed that the five included RCTs were of medium quality, and the 11 included CCTs were grade B, with a moderate risk of bias. In addition, some of the outcome indicators included in this systematic review had mostly a high level of heterogeneity.

Further large-sample and high-quality clinical trials are necessary. An additional limitation of this review was that the literature on the long-term efficacy of functional appliances is limited, and thus, this study failed to explore the long-term stability of activator treatment. Also, longterm studies are needed to assess the stability of its effect on the skeletal, dental, and soft tissue changes. In terms of soft tissue effects, since the quantity and quality of the articles 
included are limited, more qualified RCTs are required to provide reliable evidence regarding this issue.

\section{Conclusions}

Compared with untreated control subjects, the results showed that activator appliance therapy restrained sagittal maxillary growth, increased mandibular length (Co-Gn and/or Go-Me), rotated the mandible backward, and increased the lower facial height. Subsequently, the position of the relationship between the mandible and maxilla was improved. Growing skeletal Class II malocclusion patients exhibited significant reductions in the overjet and overbite after activator treatment. In addition, the upper incisors demonstrated a great degree of retrusion, the inclination of upper incisor teeth (U1-SN) decreased, and lower incisors showed some proclamation (L1-MP). The UL-E of patients decreased after treatment with the activator appliance; however, studies of the LL-E reported contradictory results.

\section{Acknowledgments}

Funding: This work was supported by the National Nature Scientific Foundation of China (No. 81960195) and the National Nature Scientific Foundation of China (No. 81660178).

\section{Footnote}

Reporting Checklist: The authors have completed the PRISMA reporting checklist. Available at https://dx.doi. org/10.21037/apm-21-3205

Conflicts of Interest: All authors have completed the ICMJE uniform disclosure form (available at https://dx.doi. org/10.21037/apm-21-3205). The authors have no conflicts of interest to declare.

Ethical Statement: The authors are accountable for all aspects of the work in ensuring that questions related to the accuracy or integrity of any part of the work are appropriately investigated and resolved.

Open Access Statement: This is an Open Access article distributed in accordance with the Creative Commons Attribution-NonCommercial-NoDerivs 4.0 International License (CC BY-NC-ND 4.0), which permits the noncommercial replication and distribution of the article with the strict proviso that no changes or edits are made and the original work is properly cited (including links to both the formal publication through the relevant DOI and the license). See: https://creativecommons.org/licenses/by-nc-nd/4.0/.

\section{References}

1. McNamara JA Jr. Components of class II malocclusion in children 8-10 years of age. Angle Orthod 1981;51:177-202.

2. Pancherz H. A cephalometric analysis of skeletal and dental changes contributing to Class II correction in activator treatment. Am J Orthod 1984;85:125-34.

3. Idris G, Hajeer MY, Al-Jundi A. Soft- and hard-tissue changes following treatment of Class II division 1 malocclusion with Activator versus Trainer: a randomized controlled trial. Eur J Orthod 2019;41:21-8.

4. Graber TM. Functional appliances. In: Graber TM, Vanarsdall RL, Vig KWL (eds). Orthodontics, current principles and techniques. 4th ed. St Louis: Mosby, 2005:493-542.

5. Ahlgren J, Laurin C. Late results of activator-treatment: a cephalometric study. Br J Orthod 1976;3:181-7.

6. Marsico E, Gatto E, Burrascano M, et al. Effectiveness of orthodontic treatment with functional appliances on mandibular growth in the short term. Am J Orthod Dentofacial Orthop 2011;139:24-36.

7. Hashim HA. Analysis of activator treatment changes. Aust Orthod J 1991;12:100-4.

8. Cozza P, Baccetti T, Franchi L, et al. Mandibular changes produced by functional appliances in Class II malocclusion: a systematic review. Am J Orthod Dentofacial Orthop 2006;129:599.e1-12; discussion e1-6.

9. Tulloch JF, Phillips C, Koch G, et al. The effect of early intervention on skeletal pattern in Class II malocclusion: a randomized clinical trial. Am J Orthod Dentofacial Orthop 1997;111:391-400.

10. Koretsi V, Zymperdikas VF, Papageorgiou SN, et al. Treatment effects of removable functional appliances in patients with Class II malocclusion: a systematic review and meta-analysis. Eur J Orthod 2015;37:418-34.

11. Higgins JPT, Green S (editors). Cochrane Handbook for Systematic Reviews of Interventions. Version 5.1.0. The Cochrane Collaboration, 2011. Available online: http:// www.cochrane-handbook.org

12. Jadad AR, Moore RA, Carroll D, et al. Assessing the quality of reports of randomized clinical trials: is blinding necessary? Control Clin Trials 1996;17:1-12.

13. Basciftci FA, Uysal T, Büyükerkmen A, et al. The effects of 
activator treatment on the craniofacial structures of Class II division 1 patients. Eur J Orthod 2003;25:87-93.

14. Bilgiç F, Başaran G, Hamamci O. Comparison of Forsus FRD EZ and Andresen activator in the treatment of class II, division 1 malocclusions. Clin Oral Investig 2015;19:445-51.

15. Courtney M, Harkness M, Herbison P. Maxillary and cranial base changes during treatment with functional appliances. Am J Orthod Dentofacial Orthop 1996;109:616-24.

16. Cozza P, De Toffol L, Colagrossi S. Dentoskeletal effects and facial profile changes during activator therapy. Eur J Orthod 2004;26:293-302.

17. Dalci O, Altug AT, Memikoglu UT. Treatment effects of a twin-force bite corrector versus an activator in comparison with an untreated Class II sample: a preliminary report. Aust Orthod J 2014;30:45-53.

18. Erdem A, Kilic N, Eröz B. Changes in soft tissue profile and electromyographic activity after activator treatment. Aust Orthod J 2009;25:116-22.

19. Forsberg CM, Odenrick L. Skeletal and soft tissue response to activator treatment. Eur J Orthod 1981;3:247-53.

20. Jakobsson SO, Paulin G. The influence of activator treatment on skeletal growth in Angle Class II: 1 cases. A roentgenocephalometric study. Eur J Orthod 1990;12:174-84.

21. Lall R, Kumar GA, Maheshwari A, et al. A retrospective cephalometric evaluation of dental changes with activator and activator headgear combination in the treatment of skeletal class II malocclusion. J Contemp Dent Pract

Cite this article as: Xie J, Huang C, Yin K, Park J, Xu Y. Effects of orthodontic treatment with activator appliance on patients with skeletal Class II malocclusion: a systematic review and meta-analysis. Ann Palliat Med 2021;10(12):12319-12334. doi: 10.21037/apm-21-3205
2011;12:14-8.

22. Looi LK, Mills JR. The effect of two contrasting forms of orthodontic treatment on the facial profile. Am J Orthod 1986;89:507-17.

23. Nelson C, Harkness M, Herbison P. Mandibular changes during functional appliance treatment. Am J Orthod Dentofacial Orthop 1993;104:153-61.

24. Oztürk Y, Tankuter N. Class II: a comparison of activator and activator headgear combination appliances. Eur J Orthod 1994;16:149-57.

25. Tümer N, Gültan AS. Comparison of the effects of monoblock and twin-block appliances on the skeletal and dentoalveolar structures. Am J Orthod Dentofacial Orthop 1999;116:460-8.

26. Türkkahraman H, Sayin MO. Effects of activator and activator headgear treatment: comparison with untreated Class II subjects. Eur J Orthod 2006;28:27-34.

27. Uzuner DF, Darendeliler N, Yucel E. Combined fixedfunctional treatment of skeletal class II malocclusions with the EVAA appliance: a preliminary study. J Orofac Orthop 2014;75:275-86.

28. Varlik SK, Gültan A, Tümer N. Comparison of the effects of Twin Block and activator treatment on the soft tissue profile. Eur J Orthod 2008;30:128-34.

29. Batista KB, Thiruvenkatachari B, Harrison JE, et al. Orthodontic treatment for prominent upper front teeth (Class II malocclusion) in children and adolescents. Cochrane Database Syst Rev 2018;3:CD003452.

(English Language Editor: A. Kassem) 